подобного анализа на выборке мужчин, анализ гендерной и этнической специфики выявленных закономерностей.

\title{
Литература
}

1. Аргайл М. Психология счастья. / Пер. с англ. А.Лисициной- СПб., изд-во «Питер», 2003.-272c.

2. Клюева Н.В. Влияние семейного сценария на удовлетворенность браком// Вестник Ярославского государственного университета им.П.Г.Демидова- 2012- №2, с.128-133

3. Погорелова Е.И., Барбурова Е.Е. Жизнестойкость семейных пар и удовлетворенность браком// Психология стресса и совладающего поведения. Ресурсы, здоровье, развитие. Материалы IV Международной научной конференции: в 2-х томах. /Отв. редакторы: Т.Л. Крюкова, М.В. Сапоровская, С.А.Хазова. - Кострома, 2016, с.87-89

\section{ЭФФЕКТИВНОСТЬ АКТИВНОСТИ СОВРЕМЕННЫХ РОССИЙСКИХ ПОКОЛЕНИЙ}

Пищик В.И.

В настоящее время мы живем в изменяющемся мире, в мире «текучей реальности». Критерии оценки деятельности человека эфемерны и неустойчивы, поскольку подвижны и изменчивы критерии и границы реальности. В этой связи становится актуальной проблема оценки эффективности деятельности персонала. Но мы бы хотели перейти к оценке эффективности не вообще персонала, а его представителей, относящихся к различным группам поколений. Выделяют поколение, победившее во второй мировой войне, «потерянное» поколение или творческое поколение 60-гг., поколение застоя, поколение «пепси». В обществе существует различное отношение к типам поколений. Оно оценивается как более эффективное или менее. Сегодня мир кординально изменился. Очень много свобод и возможностей. Человек должен знать, что ему делать со своей свободой. Современным типом неопределенности является не отсутствие средств, а отсутствие и поиск целей [4]. Поскольку обществом не управляет традиция, то количество возможностей растет. Не хватает правил, паттернов и кодексов, которые определили бы ориентиры движения [1, с. 13]. Эпоха референтных групп закончилась, наступила эпоха тотального сравнения со всеми. При постоянно растущих возможностях потребности человека удовлетворяются, но не на долго. Сегодня усилия, прилагаемые к достижению цели, изменяются со временем и возникнет неопределенность. В этой связи представляется, что размыты критерии эффективности и как бы мы их искусственно не создавали, они изменятся через какое-то время и придется создавать новые критерии. Критериев великое множество и они часто противоречат друг другу.

Одним из критериев эффективности социальных форм сегодня является скорость и мобильность, умение меняться, которые являются основой власти и доминирования в современном обществе. Субъективно время жизни сжимается, плотность времени растет. Благодаря Интернету изменилось отношение к 
пространству. Характеристикой прошлого являлась привязанность к месту, к определенному офису, обслуживание которого дорого обходилось, сегодня мы можем иметь виртуальный офис. Уходят вечные языковые константы «близко/далеко», «долговременное/кратковременное», «надежность/зыбкость». Работа сегодня это - краткосрочный договор, «палаточный лагерь» [1, с. 161]. Зависимости и взаимодействие подвижны и постоянно меняют свою форму.

Мы перешли от общества производителей к обществу потребителей. Производство основано на сотрудничестве, а потребление основано на индивидуальности. Чем больше вариантов выбора, тем выше производительность. Источником прибыли становятся идеи, а не материальные объекты. Сложность и сопротивление поддерживают включенность работника в деятельность. Контроль, лидерство, управление заменяются на культуру, сеть, команду. Организация должна как трансформер быстро модифицироваться в новую форму. Знания быстро стареют и важно действовать в соответствии с новым опытом - принцип эффективности. Никто не хочет ждать, требование мгновенности вознаграждения.

Человек может не успеть в мире структурной безработицы. Нет гарантий, что работа, которая будет предложена, окажется постоянной. Именно поэтому связи и партнерство порой оцениваются как вещи, которые работники используют, а не создают. Если партнерские отношения не приносят удовлетворения, то их разрывают. Из-за этого так трудно создать атмосферу доверия в организации.

При этом каждый человек является представителем определенного поколения, что определяет его тип ментальности и возможности в мире. Если обратиться к концепции поколений W. Strauss, N. Howe [5], то они обращали внимание на некоторую миссию поколения: например, поколение пророков, поколение героев, художников.

Сегодня наибольшую активность в рабочей среде составляют два поколения: переходное (1965-1982 г.р.) и информационное (1983-1999 г.р.).

Каждый из типов ментальности поколения проявляется через систему его архетипов, образ мира, образ жизни, стиль мышления, особенности отношений и взаимодействия [3]. На этом основании была создана методика измерения типа ментальности [2]. Определив тип ментальности у переходного и информационного поколений (250 чел., г. Ростов-на-Дону, сотрудники крупной компании), мы увидели, какие составляющие типа ментальности у них выражены. Провели анкету по вопросам лояльности к компании. Также применили методику выявления ценностной обусловленности социальной идентификации Сикевич 3.В. (2006) для выявления качеств, преобладающих у поколения; измерили стратегии поведения в конфликте (опросник К. Томаса).

В группе переходного поколения в зоне традиции находятся только архетипы и особенности отношений к делу, себе и другим (значимость различий с остальными типами ментальности на уровне $\mathrm{p}<0,001)$. Архетипы как базовые основания ментальности играют значимую роль и определяют тип ментальности. Остальные составляющие: образ мира, образ жизни, стиль 
мышления и особенности взаимодействия находятся в зоне инновации. Но вместе с тем, только образ мира значимо отличается от традиции ( $<<0,001)$.

Переходному поколению предшествует советское поколение (1946-1964 г.р.), которое является носителем традиционной ментальности. Традиционная ментальность характеризуется коллективизмом в ценностных ориентациях, стабильным образом мира, типичным образом жизни, гомогенным дискурсом. Переходное поколение расположено между традиционной ментальностью советского поколения и инновационной ментальности информационного поколения, поэтому мы можем наблюдать сочетание традиции и инновации в составляющих переходной ментальности. Потому мы можем его обозначить как переходное поколение. Были выявлены следующие качества, преобладающие в переходном поколении: адекватная самооценка $(0,33)$, хитрость $(0,47)$, осторожность $(0,35)$, трудолюбие $(0,43)$, откровенность $(0,30)$.

В группе информационного поколения в зоне инновации находятся архетипы (но нет значимых различий с традицией), образ мира, образ жизни и особенности взаимодействия значимо выше традиции (значимость различий с остальными типами ментальности на уровне $\mathrm{p}<0,001)$. В зоне постинновации находятся стиль мышления, особенности отношений, но отличия незначимы. Таким образом, у информационного поколения преобладает инновационная ментальность, которая характеризуется индивидуализмом, нестабильным образом мира, активным образом жизни и гетерогенным дискурсом. Однако следующее поколение - это новое поколение (2000-2017 г.р.), носитель постинновационной ментальности, поэтому предполагаем, у информационного поколения проявятся особенности постинновационной ментальности.

У информационного поколения выявлены следующие качества: энергичность $(0,27)$, пассивность $(0,34)$, трудолюбие $(0,45)$, активная позиция $(0,38)$, материальное благоустройство $(0,40)$.

Мы наблюдаем особенность преобладания инновационных тенденций у поколений активных, работающих россиян. Информационное поколение, по мнению многих экспертов, имеет нереальные ожидания и завышенные требования. А переходное поколение более реалистично в силу своей традиционности.

Предпочитаемые стратегии поведения в конфликте у представителей переходного поколения - компромисс $(\mathrm{p} \leq 0,05)$, приспособление $(\mathrm{p} \leq 0,05)$. Представители информационного поколения показали наибольшую выраженность стратегий поведения в конфликте - противостояние $(\mathrm{p} \leq 0,05)$, уход $(\mathrm{p} \leq 0,001)$.

По данным анкетирования представители переходного поколения проявляют больше скептичности в оценках организации $(\mathrm{p} \leq 0,01)$ но при этом пытаются найти баланс и гибкость. Представители информационного поколения в меньшей степени проявляют лояльность к компании $(\mathrm{p} \leq 0,02)$. Тем не менее, представители информационного поколения придают большое значение интенсивным отношениям с сотрудниками и руководителем.

В анкете также были вопросы, связанные с эффективностью работы представителей поколений. Были выявлены следующие критерии 
эффективности: общие - полно выполненная работа в определенные сроки и специфические критерии у традиционного поколения - принести благо обществу; для переходного поколения - гибкость, умение не оглядываться; для информационного поколения - мобильность, умение меняться.

Таким образом, каждое поколение имеет свои специфические стратегии поведения в конфликтах, сопряженных с определенной степенью лояльности к организации и критерии эффективности.

\section{Литература}

1. Бауман 3. Текучая современность. СПб.: Питер, 2008. 240 с.

2. Pishchik V.I. Psychometric testing methods for measuring type mentality generations // European researcher = Европейский исследователь. 2013. Т. 54, № 7-1. C. 1852-1866. http://www.erjournal.ru/journals_n/1375549025.pdf

3. Pishchik V.I., Gavrilova A.V. Styles of interaction among X-generation teachers and Y-generation students // 6th. World Congress on Psychology and Behavioral Sciences (WCPBS 2016). Spain, Barcelona. pp. 77-79.

4. Schuize G. From situations to subjects: moral discourse in transition // Constructing the New Consumer society / Ed. P. Sulkunen, J. Holmwood, H. Radner, G. Schuize. New York^ Macmillan, 1997. P. 49.

5. Strauss W., Howe, N. Millennials Rising: The next great generation (vintage original). New York, 2009. 432 p.

\section{ВОЗРАСТНОЙ АСПЕКТ СУБЪЕКТНОСТИ ЛИЧНОСТИ}

Полежаева В.А.

Поведение человека с возрастом претерпевает столь же различные изменения, как и его тело. Возрастные особенности образуют определенный комплекс многообразных свойств, характеристик индивида. В отличие от широко варьирующихся индивидуальных особенностей, возрастные изменения отражают такие преобразования, которые происходят в психике большинства представителей данной возрастной категории.

В настоящее время исследование субъектности личности становится приоритетным в психологической науке. Понимание субъекта связывается отношением человека к себе как к деятелю.

Субъектность личности - способность, обеспечивающая человеку возможность осуществлять самоуправление в социальном контексте своего бытия.[2]

Цель практического исследования изучение связь возраста и субъектности личности.

Гипотезы исследования: уровень развития субъектности личности зависит от возраста и изменяется вместе с ним.

Выборка исследования составила 87 человек - 22 человека в возрасте 1617 лет; 21 человек - от 18 до 23 лет; 17 человек - от 24 до 30 лет; 15 человек в возрасте от 31 до 40 лет; 12 человек в возрасте от 41 до 50 лет.

Для выявления уровня субъектности нами был использован опросник «Уровень развития субъектности личности». Среди участников исследования 